\title{
The burden of stomach cancer in indigenous populations: a systematic review and global assessment
}

\author{
Melina Arnold, ${ }^{1,2}$ Suzanne P Moore, ${ }^{2}$ Sven Hassler, ${ }^{3}$ Lis Ellison-Loschmann, ${ }^{4}$ \\ David Forman, ${ }^{2}$ Freddie Bray ${ }^{2}$
}

\begin{abstract}
- Additional material is published online only. To view please visit the journal online (http://dx.doi.org/10.1136/ gutjnl-2013-305033).

${ }^{1}$ Department of Public Health, Erasmus University Medical Center, Rotterdam,

The Netherlands

${ }^{2}$ Section of Cancer Information, International Agency for Research on Cancer, Lyon, France

${ }^{3}$ Division of Health and Culture, Department of Nursing, Health and Culture, University West, Trollhättan, Sweden

${ }^{4}$ Centre for Public Health Research, Massey University, Wellington, New Zealand
\end{abstract}

\section{Correspondence to} Dr Melina Arnold,

Section for Cancer Information, International Agency for Research on Cancer, 150 Cours Albert Thomas, Lyon 69008, France; ArnoldM@fellows.iarc.fr

Received 5 April 2013 Revised 1 October 2013 Accepted 2 October 2013 Published Online First 23 October 2013

\begin{abstract}
Objective Stomach cancer is a leading cause of cancer death, especially in developing countries. Incidence has been associated with poverty and is also reported to disproportionately affect indigenous peoples, many of whom live in poor socioeconomic circumstances and experience lower standards of health. In this comprehensive assessment, we explore the burden of stomach cancer among indigenous peoples globally. Design The literature was searched systematically for studies on stomach cancer incidence, mortality and survival in indigenous populations, including Indigenous Australians, Maori in New Zealand, indigenous peoples from the circumpolar region, native Americans and Alaska natives in the USA, and the Mapuche peoples in Chile. Data from the New Zealand Health Information Service and the Surveillance Epidemiology and End Results (SEER) Program were used to estimate trends in incidence.
\end{abstract}

Results Elevated rates of stomach cancer incidence and mortality were found in almost all indigenous peoples relative to corresponding non-indigenous populations in the same regions or countries. This was particularly evident among Inuit residing in the circumpolar region (standardised incidence ratios (SIR) males: 3.9, females: 3.6) and in Maori (SIR males: 2.2, females: 3.2). Increasing trends in incidence were found for some groups.

Conclusions We found a higher burden of stomach cancer in indigenous populations globally, and rising incidence in some indigenous groups, in stark contrast to the decreasing global trends. This is of major public health concern requiring close surveillance and further research of potential risk factors. Given evidence that improving nutrition and housing sanitation, and Helicobacter pylori eradication programmes could reduce stomach cancer rates, policies which address these initiatives could reduce inequalities in stomach cancer burden for indigenous peoples.

\section{INTRODUCTION}

Globally, stomach cancer incidence has declined over the past 4-5 decades, but still remains a major public health problem. ${ }^{1}$ Stomach cancer is the second leading cause of cancer death worldwide, with large geographical differences in incidence and mortality in different regions and countries. ${ }^{2}$ In 2008, about three-quarters of cases and deaths from stomach cancer occurred in low- and middle-income

\section{Significance of this study}

What is already known on this subject?

- Stomach cancer is the second leading cause of cancer death worldwide and wide geographical and ethnic variations exist in its occurrence.

- Indigenous peoples carry a disproportionate burden of stomach cancer; however the extent of inequalities has not yet been quantified from a global perspective.

- Indigenous peoples often live in poor socioeconomic circumstances which has implications for their health and well-being, including a reduced access to healthcare, which may increase their risk for certain cancers.

\section{What are the new findings?}

- Stomach cancer risk in indigenous populations substantively exceeds that of their non-indigenous counterparts in a number of countries with incidence and mortality up to fivefold that of non-indigenous populations.

- By contrast with the well-established declining trends seen in most countries and regions of the world, stomach cancer incidence appears to be increasing in several indigenous groups.

How might it impact on clinical practice in the foreseeable future?

- Due to their socioeconomic circumstances and dietary habits, indigenous peoples are often at higher risk for dyspeptic disorders, in particular, stomach cancer. Increasing awareness among clinicians may help to gain control of this global public health problem.

- Future prevention and public health measures must support government policies that focus on the improvement of social conditions, for example, housing and reducing overcrowding, and need to be tailored to specific indigenous groups.

- Further research is required, including randomised trials, to assess the benefit of Helicobacter pylori eradication on stomach cancer risk in indigenous populations. In the interim, tailored guidelines for eradication in high-risk groups, especially in children, should be developed. 
and middle-income countries (LMIC). Rates are also elevated in Eastern Europe including Russia, as well as certain parts of Latin America and East Asia. ${ }^{3}$

Approximately $90 \%$ of stomach cancers are adenocarcinomas which are further divided histologically into two categories: intestinal and diffuse. ${ }^{4}$ Both types are strongly associated with Helicobacter pylori infection, ${ }^{5}$ the former more common in older patients and males and linked to dietary factors, smoking and obesity. ${ }^{167}$ The decrease in incidence over the past 40 years has occurred primarily for the intestinal type, while incidence of diffuse-type gastric cancer has remained relatively unchanged, although time trend studies in the USA report increasing rates. ${ }^{8}$ Furthermore, risk factors for cancers arising in the cardia (proximal) and the non-cardia (distal) parts of the stomach differ. Whereas cardia stomach cancers, alongside adenocarcinomas of the oesophagus, ${ }^{9}$ have been associated with obesity and gastrooesophageal reflux as main risk factors, non-cardia tumours are more common in less developed countries and positively associated with lower socioeconomic status and $H$ pylori infection. ${ }^{10}$

While public health measures, including improved sanitation, and a greater availability of fresh food have likely contributed to the steady decline of stomach cancer incidence, ${ }^{11}$ the resulting benefits have not necessarily been transferred equitably to all people. Poverty-associated risk factors, such as housing density and overcrowding, remain major contributors to the disproportionate burden of stomach cancer seen in the most deprived population groups. ${ }^{12}$ A particularly high stomach cancer burden has previously been reported among some indigenous populations ${ }^{i}$ 1314 who are also typically over-represented in the lowest socioeconomic groupings in their respective countries. ${ }^{15} 16$ Although the political, social and cultural circumstances of indigenous populations are diverse and unique, historical disadvantage has continued through the process of colonisation contributing to strikingly similar patterns of poor current-day health status in many indigenous groups. ${ }^{17}$ Compared to their non-indigenous counterparts, indigenous peoples not only experience an increased burden of lifestyle diseases, such as obesity, type 2 diabetes, cardiovascular disease and mental disorders, but also retain a high prevalence of infectious diseases. ${ }^{15}$ Additionally, higher rates of these comorbid conditions, together with decreased access to treatment, have important implications for cancer outcomes, including reduced survival prospects and elevated mortality rates. ${ }^{15}$

The extent to which global inequalities of stomach cancer among indigenous peoples exist has not been systematically explored. As there is considerable heterogeneity among indigenous peoples worldwide, each group needs individual study in the context of their political and social histories, environmental factors and other health determinants in order to derive tailored public health measures. The aim of this review is to assess available evidence on the stomach cancer burden in indigenous peoples worldwide, identifying populations at increased risk of developing and dying from this cancer and highlighting trends that deserve closer attention by public health and cancer prevention specialists.

\section{METHODS}

We systematically searched the literature up to May 2013 using PubMed and regional databases (see online supplementary

${ }^{\mathrm{i}}$ For clarification and consistency, initial capitals for the term indigenous were only used if they referred to a (recognised) population group, such as Indigenous Australians, but not when they were used as an adjective to refer to indigenous peoples in general. appendix 1). The search terms and strategy, following the PRISMA guidelines, can be found in online supplementary appendix 1. Briefly, separate searches were carried out using a predefined set of population terms, complemented with geographical restrictions and epidemiological terms, with a focus on stomach cancer. Studies were included if age-standardised rates or rate ratios (incidence and/or mortality) or survival proportions in indigenous peoples (relative to non-indigenous) were reported. First, titles and abstracts were reviewed in order to identify potentially relevant studies. Subsequently, a manual search was carried out based on the references cited in the relevant papers. Case reports, reviews and editorials were excluded. Studies were grouped and reviewed based on geographical regions and ethnic/indigenous groups: circumpolar region (including Inuit, Alaska Natives, Greenlanders, Sami, Indigenous Siberians and others), USA (American Indians and Alaska Natives), South America (among others, Mapuche), Australia (Indigenous Australians) and New Zealand (Maori). Studies with results displayed in figures only were excluded; studies with less than 10 cases were included in online supplementary table S1, but were not considered in the results and the conclusion. If there was clear overlap between studies, only the most comprehensive or most recent study was included.

To complement the literature search, we analysed trends in incidence in two indigenous groups, with data from routine sources in New Zealand and the USA. Specifically, data on new cases of stomach cancer among Maori and non-Maori were available from annual reports of the New Zealand Ministry of Health $^{18}$ and among American Indians and Alaska Natives (AI/AN) from the Surveillance, Epidemiology and End Results (SEER) Program (13 registries) for the period 1995-2009. ${ }^{19}$

We calculated 3-year averaged age-standardised incidence rates using the world standard population and the estimated annual percentage change (EAPC) using joinpoint regression analysis, ${ }^{20}$ a common method in cancer epidemiology to analyse incidence and mortality trends.. Using this method, abrupt changes in long-term trends, linear segments of time during which rates are relatively stable, can be identified and tested. EAPCs were calculated by fitting connected linear trends on a log scale with calendar year as a regressor variable, assuming constant variance and uncorrelated errors, allowing for up to two joinpoints (three trend-line segments). The final model provides an estimate of the direction and magnitude of the trend between each set of joinpoints, thus avoiding the need to base trend estimation on arbitrary calendar periods. STATA V.11 and Joinpoint 4.0 were used for the statistical analyses.

\section{RESULTS}

\section{Literature search}

The search yielded 5219 studies, 74 of which were relevant for our overview (see online supplementary figure S1). Five main regions and their indigenous peoples were identified based on the results of our search: Indigenous Australians, Maori in New Zealand, indigenous peoples from the circumpolar region (including Inuit, Sami and Indigenous Siberians), Native Americans and Alaska Natives in the USA and Mapuche peoples in Chile.

\section{Incidence}

Totally, 57 studies exploring cancer incidence were included (see Methods). Stomach cancer incidence among all indigenous groups exceeded that of their non-indigenous counterparts (see online supplementary table S1). The highest rates of stomach cancer were observed in Indigenous Siberians, ${ }^{21} 22$ Mapuche $^{23}$ 


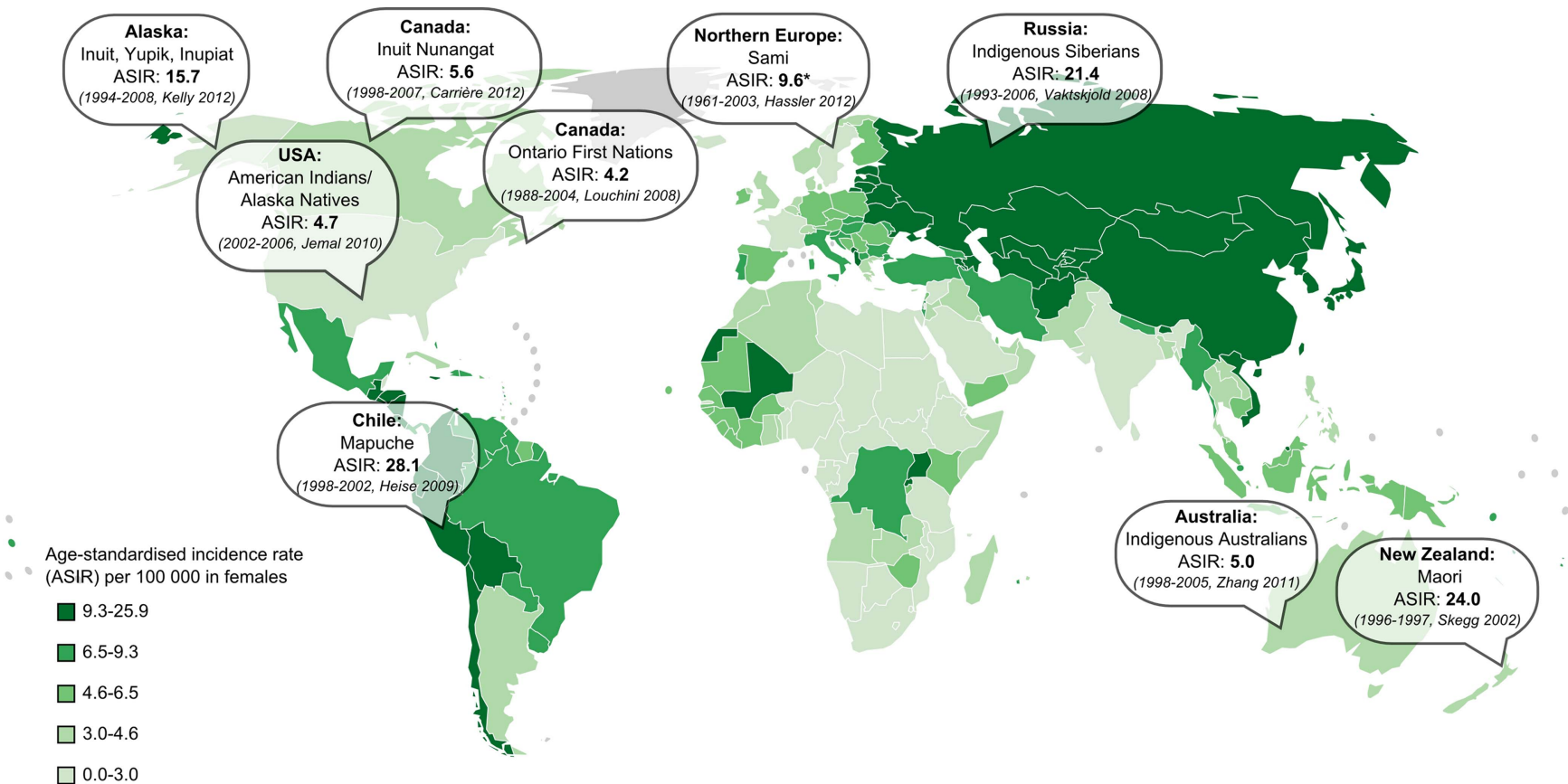

Figure 1 Global map of female stomach cancer incidence: comparisons of age-standardised incidence rates (ASIR per 100 000) in indigenous populations (years of incidence provided) versus national estimates from GLOBOCAN (2008).

and among Alaskan Inuit. ${ }^{24}$ Incidence rates in men were double those of women in most populations examined (figures 1-3).

Trends in incidence

Age-standardised incidence rates rose in male indigenous Greenlanders from 5.9 for the period $1955-1964^{25}$ to 23.4 in $1989-2003^{24}$ and similarly among Alaska Natives. ${ }^{26}$ Whereas Paltoo and colleagues ${ }^{27}$ found an increasing trend in Native
Americans and Alaska Natives between 1992 and 1999 - nonsignificant in men (EAPC: $+3.3 \%$ ) and significant in women $(+11 \%)$ - Espey and colleagues ${ }^{28}$ found significant decreases during 1975-1988 (-1.2\%) and 1988-2004 (-2.1\%).

Declining stomach cancer incidence rates after 1988 were observed in American Indians and Alaska Natives based on SEER data, ${ }^{19}$ with a significant annual decline of $8.4 \%$ among women between 1998 and 2004, and in men of $11.6 \%$ per year

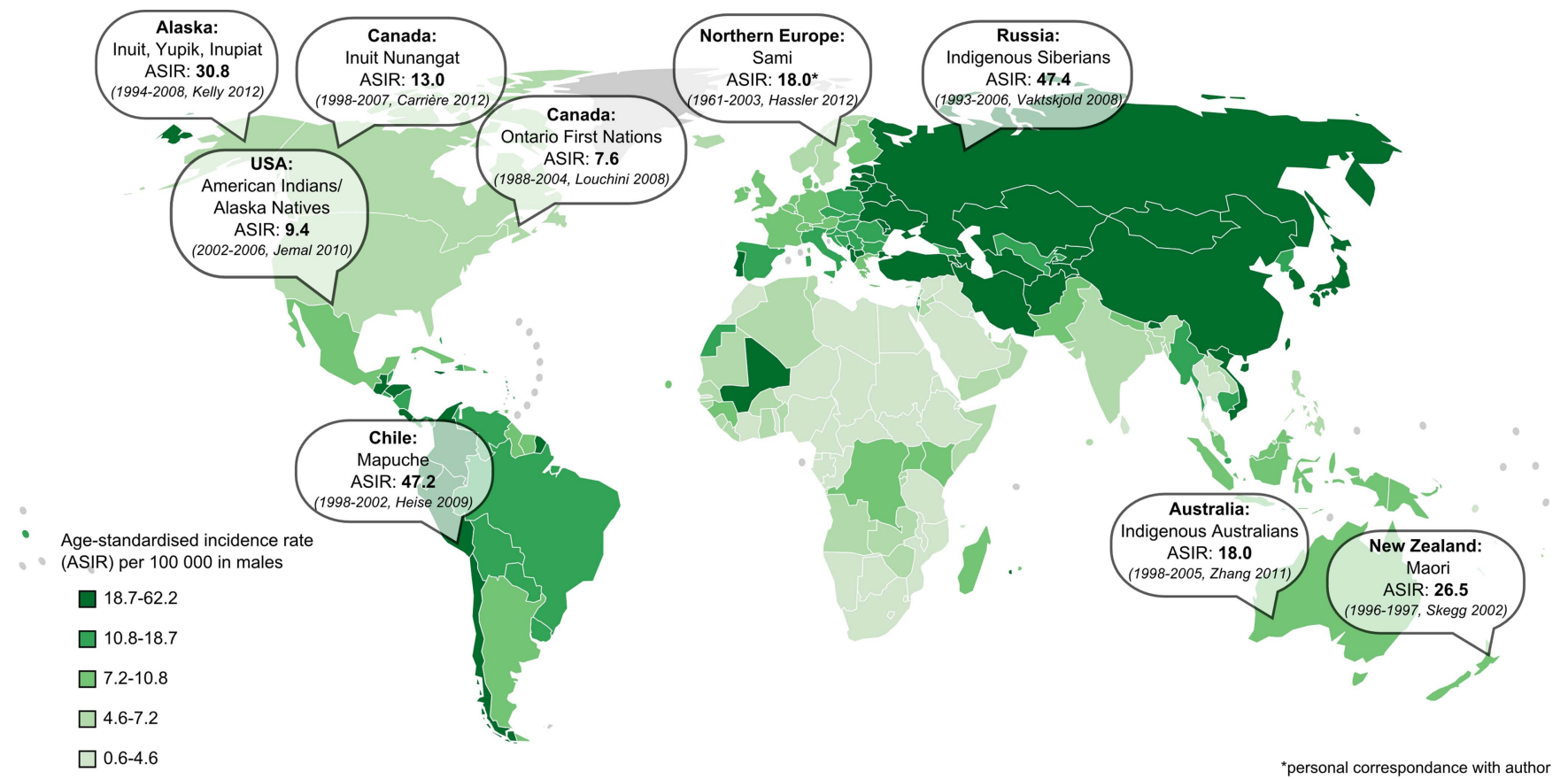

Figure 2 Global map of male stomach cancer incidence: comparisons of age-standardised incidence rates (ASIR per 100 000) in indigenous populations (years of incidence provided) versus national estimates from GLOBOCAN (2008). 


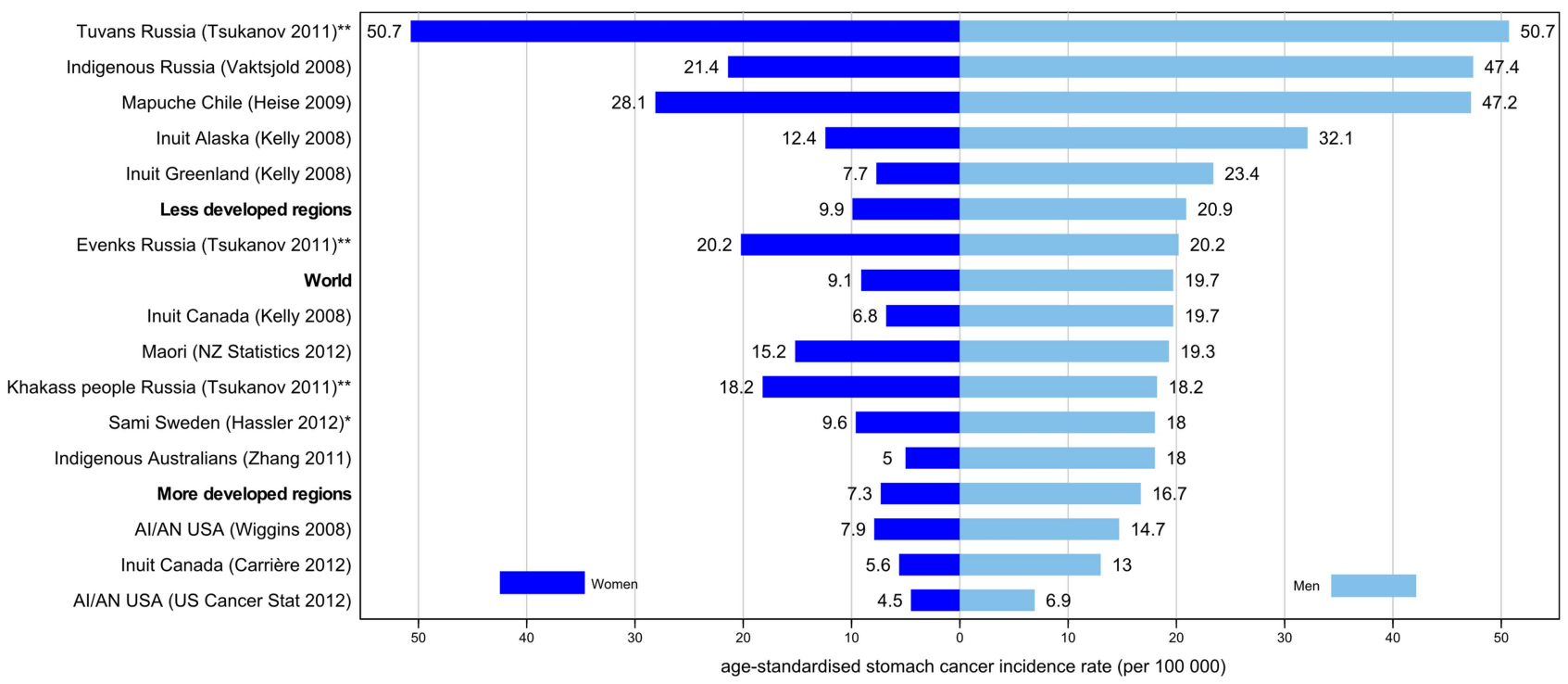

*data for Sami in Sweden was provided by Dr. Hassler

** rates for males and females combined

Figure 3 Age-standardised incidence rates (ASIR per 100 000) of stomach cancer in indigenous populations (based on literature review) by sex, with comparisons with more and less developed regions and the world (GLOBOCAN 2008).

between 2005 and 2008 (figure 4, table 1). The incidence in Maori men decreased significantly between 1963 and 1984 by $-0.8 \%$ per year, ${ }^{29}$ and more rapidly since 1996 (figure 4, table 1). However, a significant increase in incidence was observed in Maori of both sexes since 2000, in contrast with incidence rates in the non-Maori population which continued to uniformly decline (figure 4, table 1).

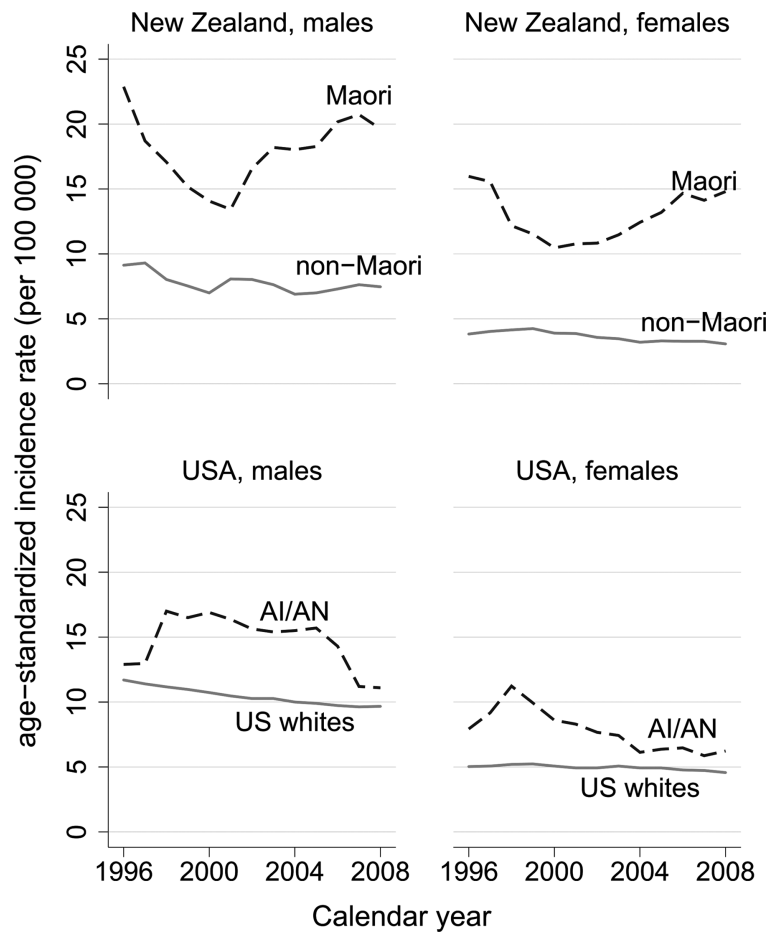

Figure 4 Trends in age-standardised* incidence rates (ASIR per 100000 ) of stomach cancer (smoothed using 3-year moving averages) in Maori and American Indians/Alaska Natives (Al/AN) 1996-2008 by sex, with comparisons with non-Maori and the US Caucasian population, (source: SEER, NZHIS).
Incidence ratios

A number of studies have compared stomach cancer in indigenous groups with non-indigenous populations using either standardised incidence ratios (SIR) or incidence rate ratios as measures of relative risk (RR) (see online supplementary table S2a). Circumpolar Inuit were at a threefold higher risk of developing stomach cancer compared with SEER whites, ${ }^{24}$ similar to Maori in New Zealand when compared to non-Maori. $^{29}$ By contrast with increased SIRs among Mapuche in Chile, ${ }^{23}$ lower risks for stomach cancer were found among the indigenous population relative to the non-indigenous population of the Amazon basin of Ecuador. ${ }^{30}$ Notably, SIRs were higher in women than men in Maori, ${ }^{29}$ Mapuche, ${ }^{23}$ $\mathrm{AI} / \mathrm{ANs}^{28} 31$ and Sami. ${ }^{32}$

Subsites

A significantly higher percentage of diffuse-type gastric cancer, and a higher incidence rate of non-cardia, distal tumours (noncardia: 9.7/7.9 per 100000 in men/women vs cardia: 0.9/0.6) have been reported in Maori. ${ }^{33}$ Low rates of cardia adenocarcinomas were also noted in American Indians and Alaska Natives (0.9 per 100000 in men, 0.2 in women), especially relative to non-indigenous Caucasians (3.4 in males, 0.9 in females) and other ethnic groups in the USA. ${ }^{34}$ High rates of non-cardia were also observed in Native Americans in the study by Brown and colleagues. ${ }^{35}$ In Alaska, the incidence of central/distal stomach cancer was significantly higher in American Indians and Alaska Natives relative to non-Hispanic whites (RR men: 5.8, 95\% CI 2.6 to 13.5 ; RR women: $14.9,95 \%$ CI 6.0 to 44.9$){ }^{31}$

\section{Mortality}

In total, 30 studies examined stomach cancer mortality among indigenous peoples (see Methods). For Maori, Dockerty et al ${ }^{29}$ reported high mortality rates from stomach cancer in men (31.4 per 100000$)$ and women (18.9) between 1950 and 1986, with annual declines of $-0.9 \%$ and $-1.3 \%$, respectively. Skegg et $a l^{36}$ observed slightly lower mortality rates among Maori 19961997 and more recently, rates decreased to 13.8 in men and 9.6 
Table 1 Estimated annual percentage change (EAPC) in the incidence of stomach cancer and its 95\% Cls for Maori and non-Maori and for American Indians/Alaska Natives (AI/AN) and US Caucasians between 1996 and 2008

\begin{tabular}{|c|c|c|c|c|c|}
\hline \multirow[b]{2}{*}{ Year } & \multicolumn{2}{|l|}{ Men } & \multirow[b]{2}{*}{ Year } & \multicolumn{2}{|c|}{ Women } \\
\hline & EAPC & $95 \% \mathrm{Cl}$ & & EAPC & $95 \% \mathrm{Cl}$ \\
\hline \multicolumn{6}{|l|}{ Maori } \\
\hline 1996-2000 & -10.3 & $(-16.3$ to -3.9$)$ & 1996-2000 & -11.2 & $(-15.2$ to -6.9$)$ \\
\hline $2000-2008$ & 5.5 & (3.0 to 8.1 ) & $2000-2008$ & 5.1 & (3.4 to 6.8 ) \\
\hline \multicolumn{6}{|l|}{ Non-Maori } \\
\hline \multirow[t]{3}{*}{ 1996-2008 } & -1.6 & $(-2.7$ to -0.4$)$ & 1996-1999 & 2.9 & $(-0.7$ to 6.7$)$ \\
\hline & & & 1999-2004 & -4.9 & $(-7.1$ to -2.8$)$ \\
\hline & & & 2004-2008 & -0.9 & (-3.1 to 1.4 ) \\
\hline \multicolumn{6}{|l|}{ Al/AN } \\
\hline 1996-1998 & 16.2 & $(-1.9$ to 37.6$)$ & 1996-1998 & 17.3 & (1.7 to 35.2 ) \\
\hline 1998-2005 & -1.0 & $(-3.8$ to 1.9$)$ & 1998-2004 & -8.4 & $(-11.3$ to -5.5$)$ \\
\hline $2005-2008$ & -11.6 & $(-18.8$ to -3.8$)$ & 2004-2008 & -1.2 & $(-5.5$ to 3.4$)$ \\
\hline \multicolumn{6}{|l|}{ US Caucasians } \\
\hline 1996-2002 & -2.1 & $(-2.5$ to -1.7$)$ & 1996-2008 & -0.8 & $(-1.2$ to -0.4$)$ \\
\hline $2002-2008$ & -1.2 & $(-1.5$ to -0.8$)$ & & & \\
\hline
\end{tabular}

in women in 2009, compared with 4.7 and 1.7 in non-Maori men and women, respectively. ${ }^{37}$ Similarly, rates among AI/ANs were higher than among other ethnic groups, reported as 9.8 in men and 4.6 in women during 2002-2006. ${ }^{38}$ Declines in mortality were also found among AI/ANs between 1975 and 1987 (-2.3\% per annum), and between 1991 and 2004 (-3.5\%). Similar (but non-significant) trends were observed among Indigenous Australians between 1977 and 2000 (EAPC: $-0.8 \%) .{ }^{39}$ Mortality rates in Indigenous Australians of 21.2 and 7.9 were estimated in men and women, respectively, in a recent study by Morrell et al. ${ }^{40}$

\section{Mortality ratios}

A high standardised mortality ratio was estimated for stomach cancer mortality among Indigenous Australian men $(2.1 ; 95 \%$ CI 1.5 to 2.9$)$ and women $(2.0 ; 1.2$ to 3.2$),{ }^{41}$ and among AI/ANs men (1.47) and women (1.77) ${ }^{42}$ (see online supplementary table S2b). By contrast, significantly lower risks were found in Ontario First Nation men. ${ }^{43}$ The risk of dying after stomach cancer was 10 times higher in Alaska Native men relative to US Caucasians $1994-2008,{ }^{44}$ while higher stomach cancer mortality was reported among Skolt Sami in Finland compared with both the overall Finnish population as well as other Sami groups. $^{45}$

\section{Survival}

Six studies reported survival from stomach cancer among indigenous peoples. Low relative survival proportions were found among Mapuche in Chile with 5 years survival only $4.4 \%$ (11.9\% in other Hispanics). ${ }^{23}$ Similarly, Young et al ${ }^{46}$ observed the lowest 5 years survival proportions among American Indians (11\% in men and $7 \%$ in women) when compared with other ethnic groups. In a study among American Indians in New Mexico and Arizona, survival differences could be explained by stage at diagnosis and treatment. ${ }^{47}$ Relative survival in American Indians climbed to 14\% between 1983 and 1994, ${ }^{48}$ however, cause-specific survival remained lowest of all ethnic groups in the USA more recently. ${ }^{49}$ Jeffreys et $a l^{50}$ found slightly lower age-standardised and stage-standardised relative survival proportions among Maori (15\%) relative to non-Maori (22\%).

\section{DISCUSSION}

Marked contrasts exist in the relative burden of stomach cancer in indigenous and non-indigenous populations included in this review, particularly among Inuit in the circumpolar region and Maori in New Zealand. Whereas incidence and mortality rates from stomach cancer have uniformly decreased in the last four decades in most parts of the world, ${ }^{51}$ rates have increased for some indigenous population groups. Incidence of stomach cancer has been associated with poor nutrition and sanitation, 52 hallmarks of poverty, and it is plausible that indigenous peoples, who are among the poorest globally, ${ }^{53}$ are affected more than other population groups. A high intake of salt may also play a key role in modifying risk in some indigenous groups, especially in the Arctic region where salt is especially prevalent in traditional foods. ${ }^{54}$ Evidence from migrant studies has shown that first-generation migrants from countries with high incidence of stomach cancer that migrate to low-incidence countries largely retain the risk profile of their country of origin. However, decreases in the incidence rate have been observed over time and in successive generations, acknowledging the strong link between stomach cancer and environmental risk factors, acting early in life. ${ }^{55} 56$

$H$ pylori infection can damage the gastrointestinal tract and is the most consistent risk factor for non-cardia gastric cancer, accounting for an estimated $75 \%$ of all distal gastric cancers according to a review of global data published in $2008 .^{52}$ However, only a minority of infected persons develop clinical signs of infection. Lifetime risks of the acquisition of peptic ulcers or distal stomach cancer in $H$ pylori-positive persons is estimated to be $10-15 \%$ and $1-2 \%$, respectively. ${ }^{57} \mathrm{H}$ pylori infection is usually acquired in childhood and is fostered by overcrowding and poverty. ${ }^{10}$ In LMICs, the prevalence of stomach cancer has been found to be similar to that of $H$ pylori infection, resulting in a much higher burden. ${ }^{58}$ Studies on the prevalence of $H$ pylori infection among indigenous peoples confirm this pattern, suggesting high rates among Maori, ${ }^{59}$ Indigenous Australians, ${ }^{60}$ as well as Arctic aboriginal populations. ${ }^{61}$ The fact that the relationship between $H$ pylori infection and stomach cancer is confined to non-cardia (distal) tumours, was confirmed in some studies that stratified by 
anatomical subsite, reporting particularly high rates of noncardia tumours in indigenous populations. ${ }^{3162}$

$H$ pylori infection is curable and comprehensive guidelines for its management have been developed. ${ }^{63}$ Elimination therapy to prevent gastric cancer has been recommended for dyspeptic persons from high-prevalence regions. ${ }^{64}$ However, the exact source of $H$ pylori is still unknown and given that infection is ubiquitous in many populations (prevalence $>80 \%$ ), elimination therapy is neither feasible nor (cost-)efficient. Additionally, elimination rates have decreased in past years due to increasing bacterial resistance to drug regimens. ${ }^{65}$ Some studies have also suggested that $H$ pylori eradication might have detrimental effects, for example, as a contributing factor to the onset of Barrett's oesophagus. ${ }^{66}{ }^{67}$ However, this relationship remains controversial and evidence is needed from clinical trials. Comprehensive public health approaches to reduce exposure to $H$ pylori infection may yield more widespread and sustainable results, including improved housing and living conditions for indigenous and poor populations who are at increased risk of developing stomach cancer.

Lifestyle factors, including nutrition and smoking habits, have both been found to be important in the development of stomach cancer. ${ }^{10}$ Maori have one of the highest smoking rates in the world and also begin smoking at a much earlier age than many other populations. ${ }^{36}$ Estimates suggest that up to $17 \%$ of stomach cancer cases may be attributable to smoking, ${ }^{1}$ with an increased risk seen in relation to duration and quantity of cigarettes smoked. ${ }^{68}$ Some studies have found obesity to be associated with an increased risk of cardia tumours but a decreased risk of non-cardia stomach cancer. ${ }^{1}$ Whereas a high consumption of fresh fruits and vegetables has been found to be protective, excess salt intake can promote early atrophic gastritis and gastric cancer. ${ }^{69}$ The diet of some indigenous peoples is characterised by a higher consumption of salt, for example, salt-cured whale meat in Alaska, Greenland and Northern Russia, ${ }^{70}$ and a lower intake of fresh fruits and vegetables. The traditional Sami diet, high in red meat and fatty fish and low in vegetables and fibre, has been reported to contribute to a higher cancer and allcause mortality. ${ }^{71}$ These dietary patterns often reflect cultural preferences and seasonal availability, as well as economic circumstances.

The reasons for the observed increase in stomach cancer incidence among indigenous groups included in this review-in striking contrast to the decreasing trends seen in their nonindigenous counterparts-are largely unknown. Although, for example, Inuit tend to have a high seroprevalence of $H$ pylori, general sociocultural and economic changes point against an increase in the prevalence of the infection. ${ }^{13}$ However, trends in inequalities may also reflect cohort differences in $H$ pylori infection rates; for example, in New Zealand where a dramatic demographic shift occurred for the majority of the Maori population who moved from rural to city environments beginning in the late 1940s-1950s. ${ }^{72}$ Similar to findings from other studies, ${ }^{1} 73$ an increased incidence of adenocarcinomas of the gastric cardia among indigenous people may relate to changes in lifestyle and higher levels of obesity. In view of the various risk factors and their possible interactions, it will be important to distinguish cardia from non-cardia stomach cancers in the future in order to shed light on the aetiological mechanisms that are responsible for changes in incidence over time. Additionally, the subtype of stomach cancer may be contributing to differing outcomes; for example, compared to non-Maori, Maori appear to experience more diffuse than intestinal stomach cancer which has a worse prognosis. ${ }^{62}$
Stomach cancer has a relatively high case fatality with a 5 -year relative survival of $24 \%$ in Europe $1995-1999^{74}$ and $27 \%$ in the USA $2002-2008 .^{75}$ The prospects of early detection measures, or interventions to reduce potential inequalities in access to treatment are thus limited, although screening, gene testing and prophylactic gastrectomy have been offered to families identified with hereditary diffuse gastric cancer since 2000 in New Zealand, and guidelines for management of familial cancer were recently updated. ${ }^{76-78}$ Hereditary diffuse stomach cancer is associated with E-cadherin gene mutations, ${ }^{79}$ and while mutations in families predominantly affected by diffuse gastric cancer have been documented, ${ }^{80}$ the reasons for the higher incidence of such sporadic cancers in Maori remains unclear. The few studies examining stomach cancer mortality or survival reported lower survival among indigenous Chileans, ${ }^{23}$ American Indians ${ }^{46-49}$ and Maori ${ }^{50} 81$ when compared to their non-indigenous counterparts. Differentials in both access to, and quality of, specialised care, as well as more advanced stage at diagnosis, have been suggested as major determinants of the survival disadvantage among indigenous groups.

\section{Strengths/Limitations}

To our knowledge this is the first assessment of the global burden of stomach cancer in indigenous populations. However, different study designs, time periods and population groups, restricted comparability. This was mainly related to difficulties in defining and identifying indigenous groups in routine datasets. These vary greatly between countries, ranging from purely geographical indicators (eg, the population of Greenland or residing on Indian reserves), to self-assigned status/ethnicity, including that linked to eligibility to access certain health services dedicated to indigenous groups (eg, the Indian Health Service), each with potential for ethnic misclassification. This may result in under-reporting of cancer in indigenous groups, which has been, for example, known to be substantial in the SEER database. ${ }^{82}$ It has therefore been proposed to use linkages with other databases and to include self-identified race in cancer surveillance data in order to improve case ascertainment in Native Americans and Alaska Natives. ${ }^{83}$

In many parts of the world, there is no routine collection of indigenous status in health data. In Latin American countries, where $10 \%$ of the population is indigenous, ${ }^{84}$ data on cancer in indigenous peoples is particularly scarce. At present, indigenous persons are usually assigned based on their self-reported knowledge of an indigenous language, and more encompassing ways to register indigenous status are still to be developed. ${ }^{30}$ Under-reporting may also explain the contrasting results from the two Latin American studies included in this overview. ${ }^{23} 30$ Additionally, even where data exist, it often remains difficult to release or gain access to these data due to restrictive policies, which is a particular issue when attempting to address health problems in small communities. ${ }^{85}$

It is important to acknowledge that in New Zealand, changes in the ethnicity definition used in successive censuses (the denominator for incidence rate calculations), which include the time period covered by our analyses, makes the calculation and comparability of data over time difficult. ${ }^{73}$ Moreover, recent work in New Zealand linking census and cancer registry data suggest Maori cancer registrations have been underestimated by between $10 \%$ and $30 \%$ since the 1980 s. $^{72}{ }^{86}$ Additionally, the advent of screening and prophylactic gastrectomy in the last 5-7 years may also have contributed to the subsequent increase in incidence rates for Maori from 2005 onwards. ${ }^{87}$ 


\section{CONCLUSION}

The high burden of stomach cancer among indigenous populations remains a public health concern. The need for careful surveillance and public health action is given added weight by the observation that stomach cancer incidence is increasing in some indigenous groups, in contrast with the well-established declining trends in the disease seen in their non-indigenous counterparts within the same regions/countries. Indigenous populations are heterogeneous with respect to their cultural, political and historical backgrounds, and differ greatly in terms of health behaviour and the prevalence and distribution of environmental risk factors; any assessment of cancer risks and implementation of prevention strategies must, therefore, reflect such differences.

In the longer term, a clearer understanding of the causes of the disparate burden of stomach cancer in indigenous populations is needed, and prevention measures developed accordingly. Clearly, optimal strategies to prevent stomach cancer on a global scale must involve improving social conditions, including reducing overcrowding and improving nutrition. In particular, efforts to further reduce salt intake and promote $H$ pylori eradication in high-risk indigenous populations could offer a means to prospectively reduce inequalities in stomach cancer risk and mortality in the future, but requires further evaluation in randomised clinical trials.

Contributors Study concept and design, acquisition of data and drafting the manuscript: MA and SPM. Analysis and interpretation of data: MA, SPM, SH, LE-L, $D F$ and $F B$. Critical revision of the manuscript for important intellectual content: $\mathrm{SH}$, LE-L, DF and FB. Study supervision: FB.

Competing interests MA has been supported by the Dutch Cancer Society. SPM is supported by an International Agency for Research on Cancer-Cancer Council Australia Postdoctoral Fellowship.

Provenance and peer review Not commissioned; externally peer reviewed.

\section{REFERENCES}

1 Forman D, Burley VJ. Gastric cancer: global pattern of the disease and an overview of environmental risk factors. Best Pract Res Clin Gastroenterol 2006;20:633-49.

2 Bray F, Jemal A, Grey $N$, et al. Global cancer transitions according to the Human Development Index (2008-2030): a population-based study. Lancet Oncol 2012;13:790-801.

3 IARC. GLOBOCAN database. IARC, 2008.

4 Lauren $P$. The two histological main types of gastric carcinoma: diffuse and so-called intestinal-type carcinoma. An attempt at a histo-clinical classification. Acta Pathol Microbiol Scand 1965;64:31-49.

5 Uemura N, Okamoto S, Yamamoto S, et al. Helicobacter pylori infection and the development of gastric cancer. N Engl J Med 2001;345:784-9.

6 Devesa SS, Blot WJ, Fraumeni JF Jr. Changing patterns in the incidence of esophageal and gastric carcinoma in the United States. Cancer 1998;83:2049-53.

7 Houghton J, Wang TC. Helicobacter pylori and gastric cancer: a new paradigm for inflammation-associated epithelial cancers. Gastroenterology 2005;128:1567-78.

8 Henson DE, Dittus C, Younes $\mathrm{M}$, et al. Differential trends in the intestinal and diffuse types of gastric carcinoma in the United States, 1973-2000: increase in the signet ring cell type. Arch Pathol Lab Med 2004;128:765-70.

9 Wijnhoven BP, Siersema PD, Hop WC, et al. Adenocarcinomas of the distal oesophagus and gastric cardia are one clinical entity. Rotterdam Oesophageal Tumour Study Group. Br J Surg 1999;86:529-35.

10 Crew KD, Neugut Al. Epidemiology of gastric cancer. World J Gastroenterol 2006;12:354-62.

11 Ushijima T, Sasako M. Focus on gastric cancer. Cancer Cell 2004;5:121-5.

12 Barker DJ, Coggon D, Osmond C, et al. Poor housing in childhood and high rates of stomach cancer in England and Wales. Br J Cancer 1990;61:575-8.

13 Friborg JT, Melbye M. Cancer patterns in Inuit populations. Lancet Oncol 2008;9:892-900

14 Hassler S, Soininen L, Sjolander $\mathrm{P}$, et al. Cancer among the Sami-a Review on the Norwegian, Swedish and Finnish Sami Populations. Int I Circumpol Heal 2008:67:421-32

15 Gracey $M$, King M. Indigenous health part 1: determinants and disease patterns. Lancet 2009;374:65-75

16 Hall G, Patrinos HA. Indigenous Peoples Policy Brief. Still among the poorest of the poor. In: Bank TW, ed. 2012. http://siteresources.worldbank.org/EXTINDPEOPLE/ Resources/407801-1271860301656/HDNEN indigenous_clean_0421.pdf
17 Anderson I, Crengle S, Kamaka ML, et al. Indigenous health in Australia, New Zealand, and the Pacific. Lancet 2006;367:1775-85.

18 Ministry of Health. Cancer: New registrations and deaths. Annual reports 19952009. Wellington: New Zealand Ministry of Health, 2012.

19 SEER. SEER * Stat Database: Incidence-SEER 13 Regs Research Data, Nov 2012 Sub (1992-2010) Surveillance, Epidemiology, and End Results (SEER) Program. 2012. http://www.seer.cancer.gov

20 Kim HJ, Fay MP, Feuer EJ, et al. Permutation tests for joinpoint regression with applications to cancer rates. Stat Med 2000;19:335-51.

21 Tsukanov VV, Butorin NN, Maady AS, et al. Helicobacter pylori Infection, Intestinal Metaplasia, and Gastric Cancer Risk in Eastern Siberia. Helicobacter 2011;16:107-12

22 Vaktskjold A, Ungurjanu TN, Klestsjinov NM. Cancer incidence in the Nenetskij Avtonomnyj Okrug, Arctic Russia. Int J Circumpolar Health 2008;67:433-44.

23 Heise K, Bertran E, Andia ME, et al. Incidence and survival of stomach cancer in a high-risk population of Chile. World J Gastroenterol 2009;15:1854-62.

24 Kelly J, Lanier A, Santos M, et al. Cancer among the Circumpolar Inuit 1989-2003 li. Patterns and trends. Int J Circumpol Heal 2008;67:408-20.

25 Nielsen NH, Hansen JP. Gastric and colorectal cancer in Greenland. Diagnostic basis and minimum incidence. Scand J Gastroenterol 1979;14:697-703.

26 Lanier AP, Kelly JJ, Smith B, et al. Alaska Native cancer update: incidence rates 1989-1993. Cancer Epidemiol Biomarkers Prev 1996;5:749-51.

27 Paltoo DN, Chu KC. Patterns in cancer incidence among American Indians/Alaska Natives, United States, 1992-1999. Public Health Rep 2004;119:443-51.

28 Espey DK, Wu XC, Swan J, et al. Annual report to the nation on the status of cancer, 1975-2004, featuring cancer in American Indians and Alaska Natives. Cancer 2007;110:2119-52.

29 Dockerty JD, Marshall S, Fraser J, et al. Stomach cancer in New Zealand: time trends, ethnic group differences and a cancer registry-based case-control study. Int J Epidemiol 1991;20:45-53.

30 San Sebastian M, Hurtig AK. Cancer among indigenous people in the Amazon Basin of Ecuador, 1985-2000. Rev Panam Salud Publica 2004;16:328-33.

31 Wiggins CL, Perdue DG, Henderson JA, et al. Gastric cancer among American Indians and Alaska Natives in the United States, 1999-2004. Cancer 2008;113:1225-33.

32 Hassler S, Sjolander P, Gronberg H, et al. Cancer in the Sami population of Sweden in relation to lifestyle and genetic factors. Eur J Epidemiol 2008;23:273-80.

33 Armstrong RW, Borman B. Trends in incidence rates of adenocarcinoma of the oesophagus and gastric cardia in New Zealand, 1978-1992. Int J Epidemiol 1996;25:941-7.

34 Kubo A, Corley DA. Marked multi-ethnic variation of esophageal and gastric cardia carcinomas within the United States. Am J Gastroenterol 2004;99:582-8.

35 Brown LM, Devesa SS. Epidemiologic trends in esophageal and gastric cancer in the United States. Surg Oncol Clin N Am 2002;11:235-56.

36 Skegg DC, McCredie MR. Comparison of cancer mortality and incidence in New Zealand and Australia. N Z Med J 2002;115:205-8.

37 Ministry of Health. Cancer: New registrations and deaths 2009. Wellington: Ministry of Health, 2012. http://www.health.govt.nz/publication/cancer-new-registrationsand-deaths-2009

38 Jemal A, Siegel R, Xu J, et al. Cancer statistics, 2010. CA Cancer J Clin 2010;60:277-300.

39 Condon JR, Barnes T, Cunningham J, et al. Long-term trends in cancer mortality for Indigenous Australians in the Northern Territory. Med J Australia 2004;180:504-7.

40 Morrell S, You H, Baker D. Estimates of cancer incidence, mortality and survival in aboriginal people from NSW, Australia. BMC Cancer 2012;12:168.

41 Moore SP, O'Rourke PK, Mallitt KA, et al. Cancer incidence and mortality in Indigenous Australians in Queensland, 1997-2006. Med J Australia 2010;193:590-3.

42 Espey D, Paisano R, Cobb N. Regional patterns and trends in cancer mortality among American Indians and Alaska Natives, 1990-2001. Cancer 2005; 103:1045-53.

43 Marrett LD, Chaudhry M. Cancer incidence and mortality in Ontario First Nations, 1968-1991 (Canada). Cancer Causes Control 2003;14:259-68.

44 Kelly JJ, Schade TL, Starkey BM, et al. Cancer in Alaska Native People 1969-2008. 40-Year Report. Alaska Native Tumor Registry, Alaska Native Epidemiology Center, Division of Community Health Services, Alaska Native Tribal Health Consortium, 2012.

45 Soininen L, Pukkala E. Mortality of the Sami in Northern Finland 1979-2005. Int J Circumpol Heal 2008;67:43-55.

46 Young JL Jr, Ries LG, Pollack ES. Cancer patient survival among ethnic groups in the United States. J Natl Cancer Inst 1984:73:341-52.

47 Samet JM, Key CR, Hunt WC, et al. Survival of American Indian and Hispanic cancer patients in New Mexico and Arizona, 1969-82. J Natl Cancer Inst 1987;79:457-63.

48 Gilliland FD, Hunt WC, Key CR. Trends in the survival of American Indian, Hispanic, and Non-Hispanic white cancer patients in New Mexico and Arizona, 1969-1994. Cancer 1998;82:1769-83.

49 Jemal $A$, Clegg LX, Ward E, et al. Annual report to the nation on the status of cancer, 1975-2001, with a special feature regarding survival. Cancer 2004; 101:3-27. 
50 Jeffreys $\mathrm{M}$, Stevanovic $\mathrm{V}$, Tobias $\mathrm{M}$, et al. Ethnic inequalities in cancer survival in New Zealand: Linkage study. Am J Public Health 2005;95:834-7.

51 Bertuccio P, Chatenoud L, Levi F, et al. Recent patterns in gastric cancer: a global overview. Int J Cancer 2009;125:666-73.

52 de Martel C, Ferlay J, Franceschi S, et al. Global burden of cancers attributable to infections in 2008: a review and synthetic analysis. Lancet Oncol 2012;13:607-15.

53 Carino J. Chapter 1: Poverty and Well-being. State of the World's Indigenous Peoples. New York: United Nations. Department of Economic and Social Affairs, 2009.

54 Elliott P, Brown I. Sodium intakes around the world. Geneva: WHO, 2007.

55 Mousavi SM, Sundquist K, Hemminki K. Does the risk of stomach cancer remain among second-generation immigrants in Sweden? Gastric Cancer 2012;15:213-15.

56 Kamineni A, Williams MA, Schwartz SM, et al. The incidence of gastric carcinoma in Asian migrants to the United States and their descendants. Cancer Causes Control 1999; 10:77-83.

57 Kusters JG, van Vliet AH, Kuipers EJ. Pathogenesis of Helicobacter pylori infection. Clin Microbiol Rev 2006;19:449-90.

58 Parkin DM. International variation. Oncogene 2004;23:6329-40.

59 Fraser AG, Peng SL, Jass JR. Intestinal metaplasia subtypes and Helicobacter pylori infection: a comparison of ethnic groups in New Zealand. I Gastroenterol Hepatol 1998;13:560-5.

60 Windsor HM, Abioye-Kuteyi EA, Leber JM, et al. Prevalence of Helicobacter pylori in Indigenous Western Australians: comparison between urban and remote rural populations. Med J Aust 2005;182:210-13.

61 Goodman KJ, Jacobson K, Veldhuyzen van Zanten S. Helicobacter pylori infection in Canadian and related Arctic Aboriginal populations. Can I Gastroenterol 2008:22:289-95.

62 Biggar M, Srinivasa S, Wickramarachchi B, et al. Gastric cancer location and histological subtype in Pacific people and Maori defies international trends. N Z Med J 2011;124:39-44.

63 Malfertheiner P, Megraud F, O'Morain CA, et al. Management of Helicobacter pylori infection-the Maastricht IV/ Florence Consensus Report. Gut 2012;61:646-64.

64 NZGG. Management of Dyspepsia and Heartburn. Evidence-based best practice guideline. Wellington: New Zealand Guidelines Group, 2004

65 Urgesi R, Cianci R, Riccioni ME. Update on triple therapy for eradication of Helicobacter pylori: current status of the art. Clin Exp Gastroenterol 2012;5:151-7.

66 Blaser M. Antibiotic overuse: stop the killing of beneficial bacteria. Nature 2011:476:393-4.

67 Blaser MJ. Helicobacter pylori and esophageal disease: wake-up call? Gastroenterology 2010;139:1819-22.

68 Tredaniel J, Boffetta P, Buiatti E, et al. Tobacco smoking and gastric cancer: review and meta-analysis. Int J Cancer 1997;72:565-73.

69 Kelley JR, Duggan JM. Gastric cancer epidemiology and risk factors. I Clin Epidemiol 2003;56:1-9.
70 Kozlov A. Impact of economic changes on the diet of Chukotka Natives. Int $\mathrm{J}$ Circumpolar Health 2004;63:235-42.

71 Nilsson LM, Winkvist A, Brustad M, et al. A traditional Sami diet score as a determinant of mortality in a general northern Swedish population. Int I Circumpol Heal 2012;71:1-12.

72 Blakely T, Shaw C, Atkinson J, et al. Cancer Trends: Trends in Incidence by Ethnic and Socioeconomic Group, New Zealand 1981-2004. Wellington: University of Otago, and Ministry of Health, 2010.

73 Maclnnis RJ, English DR, Hopper JL, et al. Body size and composition and the risk of gastric and oesophageal adenocarcinoma. Int I Cancer 2006;118:2628-31.

74 Sant M, Allemani C, Santaquilani M, et al. EUROCARE-4. Survival of cancer patients diagnosed in 1995-1999. Results and commentary. Eur I Cancer 2009;45:931-91.

75 SEER. SEER Stat Fact Sheets: Stomach. Bethesda: National Cancer Institute (NCI), 2012

76 Blair V, Martin I, Shaw D, et al. Hereditary diffuse gastric cancer: diagnosis and management. Clin Gastroenterol Hepatol 2006;4:262-75.

77 Fitzgerald RC, Hardwick R, Huntsman D, et al. Hereditary diffuse gastric cancer: updated consensus guidelines for clinical management and directions for future research. J Med Genet 2010:47:436-44.

78 Blair VR. Familial gastric cancer: genetics, diagnosis, and management. Surg Oncol Clin N Am 2012;21:35-56.

79 Guilford P, Hopkins J, Harraway J, et al. E-cadherin germline mutations in familial gastric cancer. Nature 1998;392:402-5.

80 Guilford PJ, Hopkins JB, Grady WM, et al. E-cadherin germline mutations define an inherited cancer syndrome dominated by diffuse gastric cancer. Hum Mutat 1999;14:249-55

81 Jeffreys $M$, Stevanovic $V$, Tobias $M$, et al. Ethnic inequalities in cancer survival in New Zealand: linkage study. Am J Public Health 2005;95:834-7.

82 Frost F, Taylor V, Fries E. Racial misclassification of Native Americans in a surveillance, epidemiology, and end results cancer registry. J Natl Cancer Inst 1992;84:957-62.

83 Hoopes MJ, Taualii M, Weiser TM, et al. Including self-reported race to improve cancer surveillance data for American Indians and Alaska Natives in Washington state. J Registry Manag 2010;37:43-8.

84 Hall G, Patrinos HA. Indigenous Peoples, Poverty and Human Development in Latin America, 1994-2004. 2006.

85 Colquhoun A, Aplin L, Geary J, et al. Challenges created by data dissemination and access restrictions when attempting to address community concerns: individual privacy versus public wellbeing. Int I Circumpolar Health 2012;71:1-7.

86 Cormack D, Harris R. Issues in monitoring Māori health and ethnic disparities: an update. Wellington, 2009. http://www.ethnicity.maori.nz/files/booklet_v3a.pdf

87 Blair V, Kahokehr A, Sammour T. Cancer in Maori: lessons from prostate, colorectal and gastric cancer and progress in hereditary stomach cancer in New Zealand. ANZ J Surg 2013;83:42-8. 


\section{GUT}

The burden of stomach cancer in indigenous populations: a systematic review and global assessment

Melina Arnold, Suzanne P Moore, Sven Hassler, Lis Ellison-Loschmann, David Forman and Freddie Bray

Gut 2014 63: 64-71 originally published online October 23, 2013 doi: 10.1136/gutjnl-2013-305033

Updated information and services can be found at:

http://gut.bmj.com/content/63/1/64

These include:

Supplementary Supplementary material can be found at:

Material http://gut.bmj.com/content/suppl/2013/10/23/gutjnl-2013-305033.DC1. html

References This article cites 74 articles, 9 of which you can access for free at: http://gut.bmj.com/content/63/1/64\#BIBL

Email alerting Receive free email alerts when new articles cite this article. Sign up in the service box at the top right corner of the online article.

Topic Articles on similar topics can be found in the following collections

Collections

Pancreatic cancer (646)

Stomach and duodenum (1685)

\section{Notes}

To request permissions go to:

http://group.bmj.com/group/rights-licensing/permissions

To order reprints go to:

http://journals.bmj.com/cgi/reprintform

To subscribe to BMJ go to:

http://group.bmj.com/subscribe/ 